\title{
ARCHITECTURAL EVALUATION THROUGH STAKEHOLDERS’ PARTICIPATION ON THE DEVELOPMENT OF CONSERVATION CONCEPTUAL FRAMEWORK FOR PHRA THAT THA UTHEN TEMPLE SITE IN THE NORTHEAST OF THAILAND
}

\author{
P. Don-onsa ${ }^{1}$, N. Thungsakul ${ }^{2,3 *}$ \\ ${ }^{1}$ Master of Architecture Program, Faculty of Architecture, Khon Kaen University, Thailand - prapas828@gmail.com \\ ${ }^{2}$ Centre for Research on Plurality in the Mekong Region (CERP) \\ ${ }^{3}$ Faculty of Architecture, Khon Kaen University, Thailand - nopthu@kku.ac.th
}

Commission II - WG II/8

KEY WORDS: Architectural Evaluation, Participatory Process, Architectural Conservation Framework, Religious Building, Northeast of Thailand

\begin{abstract}
:
Phra That Tha Uthen stupa is one of the most sacred religious monuments in both Thailand and Lao.PDR. In 1994, the site was registered as National Monument by the Fine Arts Department, Ministry of Culture. Since its location is in the upper north-eastern region of Thailand, it has been worshipped by both Thais and Laotians. In 2002, the Tourism Authority of Thailand promoted cultural tourism along with the provincial policy for supporting tourism along the Mekong River in 2008, the site has provoked interests among visitors as well as national and local participants towards the site. Currently, the site and its architecture encounter problems from the differences in understanding of architecture and value perceived by conservationists and stakeholders. Several sectors including the Fine Arts Department, local government agencies and related private organizations have increasingly intense difficulties managing the site because of the variety of interests and understanding of conservation concepts. Conflicts in conservation and organizing development plan for the site have been experienced. This paper thus aims to explore different viewpoints in the understanding and evaluation of architectural value of Phra That Tha Uthen Temple for the different stakeholders through a participatory process. Findings from the research can initiate possible solutions for creating the ground in terms of knowledge of architectural value from stakeholders's participation. It is expected that this study is another way to create a process to stimulate and suggest an appropriate framework for architectural conservation.
\end{abstract}

\section{INTRODUCTION}

\section{1 'Wat Arunyawasri' or Wat Phra That Tha Uthen}

'Wat Arunyawasri' or Wat Phra That Tha Uthen was established from the prosperity of Buddhism and Thai-Lao cultural communities on both banks of Mekong River. The name of Wat Phra That Tha Uthen (Wat in Thai language means a temple) is a symbol reflecting the meaning that connects the culture and belief of Tai-Yoh ethnic group whom resided in Tha Uthen District and in Hinboun District in Lao People's Democratic Republic.

The main factor for establishing this temple was related to the fact that Phra Archarn Si That, a Buddhist monk, brought the Buddha's relics from Yangon, Myanmar. After reaching Tha Uthen community, he invited local people to construct the stupa of Phra That Tha Uthen for placing the Buddha's relics. A stone plate nowadays remains at the temple ground with inscription relating the history of the stupa, date of the construction, name of construction leaders and prayers. The construction was carried out by workmen and technicians of Tai-Yoh ethnic group, Hinboun District, Lao PDR, Vietnam and China. After the completion of Phra That Tha Uthen, these schools of technicians had their significant roles to construct many important buildings in this district and in the area of Nakhon Phanom province.
In 1997 Phra That Tha Uthen, as a cultural heritage of the Mekong Basin with architectural values and importance at the national level was registered as a National Monument. The temple covers an area of about 2 Rai 2 Ngarn (0.4 ha). Phra That Tha Uthen stupa is under the control of the Fine Arts Department, mainly with the purpose for a restoration of the stupa. In 2014, the Fine Arts Department transferred the mission to control and manage the monument site of Phra That Tha Uthen to the Office of Tha Uthen District Municipality. At that time, the municipality cooperated with educational institutions and Office of Natural and Cultural Environmental Policy and Planning (ONEP) to conserve the old community of Tha Uthen. A part of the study's result was used to establish the Information Center of the Old Community in the area of Wat Phra That Tha Uthen and to renovate the house of Luang Poo Si That, the leader of Phra That Tha Uthen's construction, with the financing of the Office of District Municipality.

The development on construction of Wat Phra That Tha Uthen involved many people, i.e., Luang Poo Si That and clergy - the initiator on construction of this temple, Tha Uthen people, technicians and craftsmen from Nong Khai province. The temple houses a number of important buildings such as Ho Chaek (sermon hall), Sim (tradition folk ordination hall), the monk houses, the Office of District Municipality. The Office plays an important part in creating cultural and traditional activities under the Fine Arts Department and in planning a

* Corresponding author 
conservation guideline for conservation of Wat Phra That Tha Uthen (Office of Environmental Policy and Planning, 2015).

The groups of people mentioned above hold the principles and concept of conservation and interpretation of values from different points of view, which later affected the conservation of valuable architecture. (Kaewthep, 1995) and (Praputnitisarn, 2003) Some buildings have partly been damaged by improper changing. This may come from the difference of understandings of architectural values and meaning from those stakeholders, from their different concepts, experiences, roles and responsibilities.

Hence, this article is an explanation of the participation in architectural evaluation of stakeholders through the conceptual framework of architectural conservation by exemplifying the case study of 5 historic buildings. It is expected that the results can lead to the initial suggestions on a conservation process and a potential management for the site.

\subsection{Objective of the Study}

To explore different points of view from stakeholders in the area about the understanding of architectural values in Wat Phra That Tha Uthen through the participatory process on architectural evaluation by choosing 5 of 12 architectural buildings in the area of Wat Phra That Tha Uthen: (1) Luang Poo Si That House, (2) Ho Chaek, (3) Phra That Tha Uthen stupa, (4) Sim and (5) the monk's house.

\subsection{Conceptual Framework for Evaluation under the Concept of Architectural Conservation}

Architectural evaluation can be divided into 2 parts consisting of 6 aspects of various dimensions according to principles of architectural values (Feilden, 1995), (Office of Environmental Policy and Planning, 2007), (Piromruen, 2003), (Sutthitham, 1997, 1998) and (Pimonsathean, 2013) as indicating in Figure 1:

Part 1. Evaluation of the Architecture:

- Aspect 1 - Historical and Cultural Significance means such architecture has its relationship with historical events at the local or national level or related to an archaeological site.

- Aspect 2 - Architectural Significance means such architecture is the best example of that type of building, the only one building of that type of building, the most special building with extraordinary construction technique or craftsman skill, and a rare building with a unique design.

- Aspect 3 - Townscape Significance means such architecture has good relationship with the context or surrounding buildings such as supporting the viewpoint or being a composition with other architectures.

Part 2. Evaluation of Other Enhancing Factors (Tansukanun, 2016) and (Kanchatthiti, 2009):

- Aspect 4 - Financial Significance means such architecture has potentiality on creates income by itself or has supporting funds for maintenance.

- Aspect 5 - Suitability Significance means such architecture is still workable or properly supports present activities.

- Aspect 6 - Educational Significance means such architecture has potentiality as an exceptional example of an architectural case study.

6 aspects of architectural evaluation as mentioned above was evaluated by the participation of 5 groups of stakeholders whom have involved in the conservation and management of the site, namely:

- Group 1: Stakeholders and authorities with direct roles on Wat development (clergy).

- Group 2: Leaders and community philosophers.

- Group 3: The District Officers.

- Group 4: The Municipality Officers.

- Group 5: The Fine Arts Department Regional Officers.

The results of the study on architectural values would reflect stakeholder's thoughts and their acknowledgement on architectures that correlate with the possibility of conservation and management of each sector.

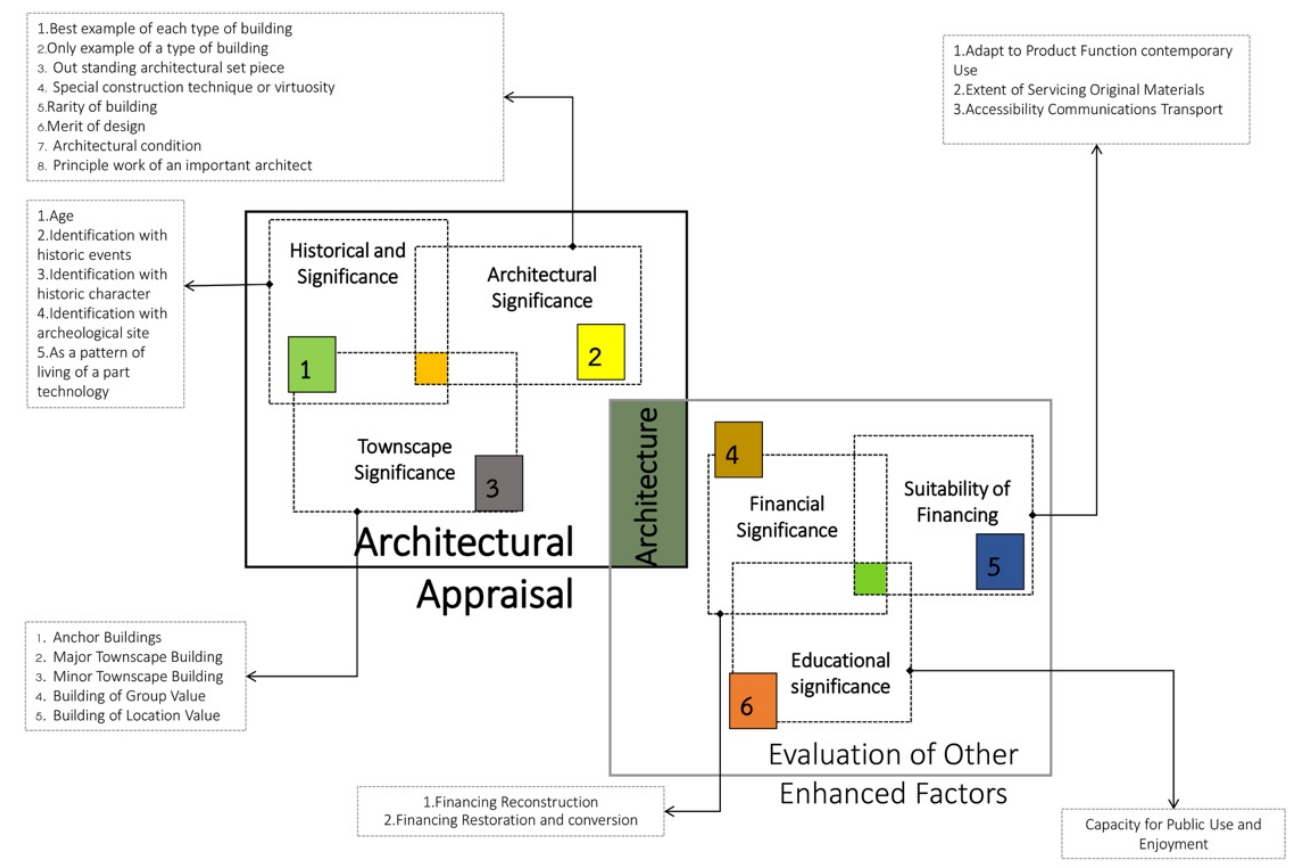

Figure 1. Conceptual Framework of Architectural Values from Relevant People in the Area. 


\subsection{History and Significance of Wat Phra That Tha Uthen}

Wat Phra That Tha Uthen is located on the bank of Mekong River in the area of Tha Uthen Old Community, Tha Uthen District, Nakhon Phanom Province, opposite to the mouth of Hinboun River, Hinboun District, Lao PDR. The stupa was established for keeping the Buddha's relics that Luang Poo Si That (the holy monk of Mekong River Basin) brought from Yangon, Myanmar around 1911. The construction of Phra That Tha Uthen stupa was completed in 1916. (Eiamanant, 2017).

Architectures in Wat Phra That Tha Uthen reflect wisdom and technology as well as represent the age and cultures associated with various ethnic groups: Lao Klang, Lao Tai, Tai-Yoh, Yuan and Thai (central region). Nowadays, Wat Phra That Tha Uthen is a cultural tourist attraction at a regional level. Figure 2 and 3 illustrate important buildings in study area.

\section{HISTORY AND SIGNIFICANCE OF ARCHITECTURES IN THE SITE}

\subsection{Luang Poo Si That House}

The building was constructed in 1902. It is a wooden structure with a 1.50 meter height underfloor space. Its design is of the Tai-Yoh ethnic house in the district. Therefore, it has demonstrated architectural value as a sample of an elevated building that reflects the way of life of agricultural society in the area, and also was the residence of Luang Poo Si That, the holy monk and the leader of Phra That Tha Uthen. In 1997, the administrative group of Wat Phra That Tha Uthen and some local residences had renovated and relocated the building from its existing location. Even though the building was renovated for several times currently it is not in use due to the belief and respect to the holy monk's spirit.

\subsection{Ho Chaek or Sermon Hall}

Ho Chaek was constructed in 1904 for performing religious ceremonies by a group of Vietnamese craftsmen. The style of
Ho Chaek is a single-storey brick and mortar building with triple hip roofs and gable. The roof structure is made of wood covered with galvanized iron roofing. The main Buddha image is situated in the building, facing the front access to the temple (the direction towards the Mekong River).

\subsection{Phra That Tha Uthen Stupa}

Luang Poo Si That constructed the stupa for 6 years starting in 1911 and finishing in 1916. Phra That Tha Uthen Stupa was constructed in the form of a 3-storey. The first floor is a tunnel to store valuable things. The second floor covers the tunnel and the third floor is the big pagoda. The stupa is square in shape, 66 meters high, and is a brick and mortar building. The stupa was restored for many times since 1992. In 1997, it was registered as a National Monument. As a result, a year later the Fine Arts Department has declared the national monument conservation zone as a restricted control boundary that under the supervision of Fine Arts Department (Figure 2).

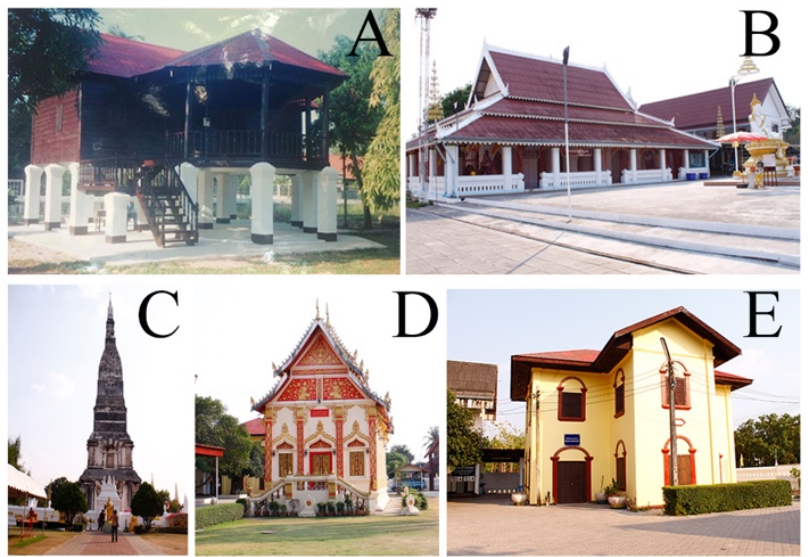

Figure 3. Architectures in Wat Phra That Tha Uthen (A) Luang Poo Si That House (B) Ho Chaek (C) Phra That Tha Uthen stupa (D) Sim (E) Monk House (WesternInfluenced Building).

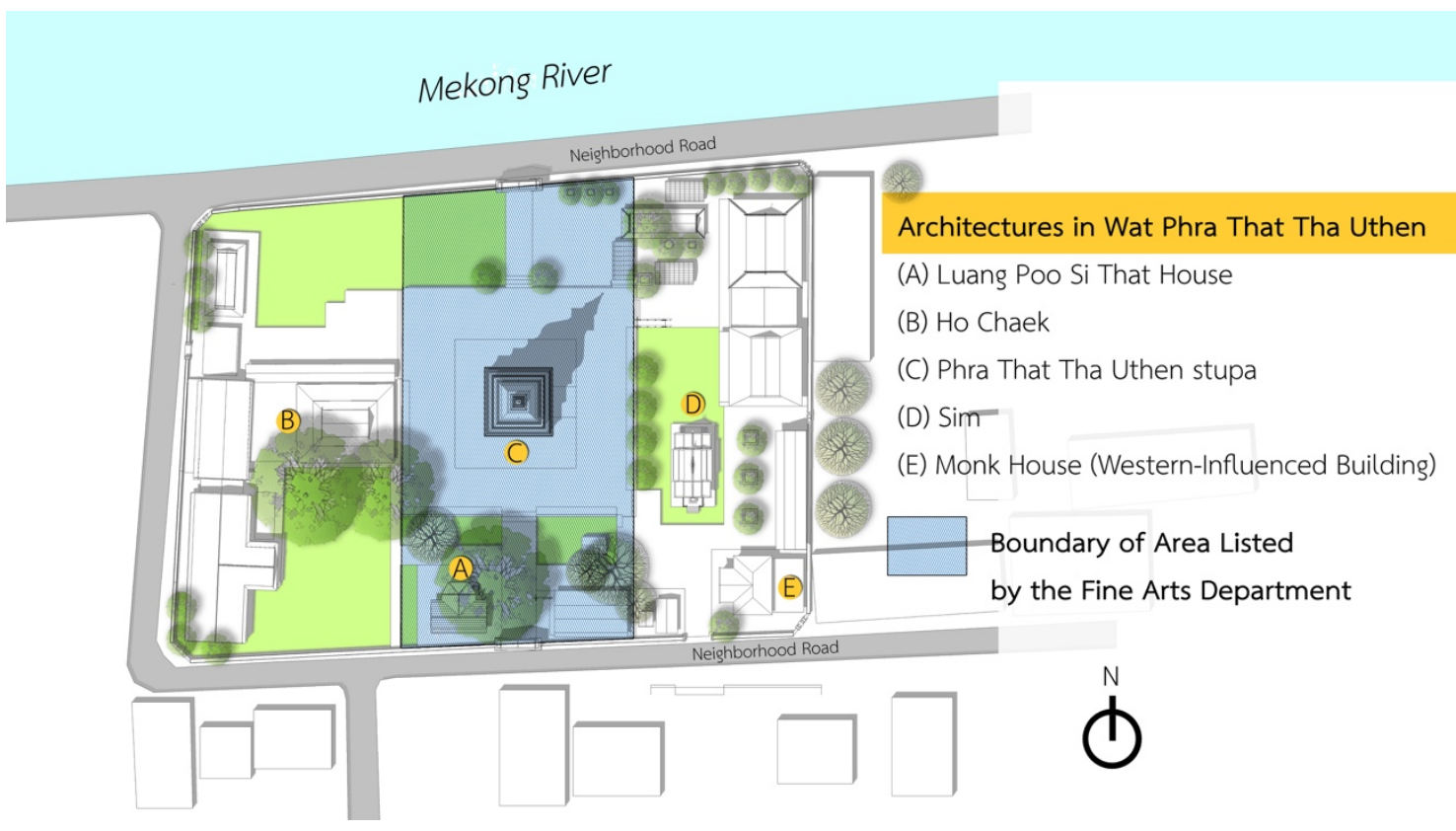

Figure 2. Boundary of Areas Listed by the Fine Arts Department and Location of Important Buildings in the Area of Wat Phra That Tha Uthen. 


\subsection{Sim or Tradition Folk Ordination Hall}

Phra That Tha Uthen Temple has a small Sim located in the front area of Phra That Tha Uthen stupa and houses a main Buddha image inside. After finishing construction of Phra That Tha Uthen stupa, that small Sim was demolished because its location was too close to the boundary of sacred zone of the stupa. The new Sim was reconstructed at the southwest of the stupa with its new main entrance at the south (The temple main entrance must be the same as the facing direction of the main Buddha image.) But the new Sim entrance was located to the opposite direction. Therefore, later in 2003 not only the main entrance of the temple was changed from the south to north, but the style of Sim was also adapted to an architecture of Lan Chang Kingdom style (the ancient kingdom of Lao PDR).

\subsection{The Monk House (Western-Influenced Building)}

The monk house was constructed in 1953 by Vietnamese craftsmen in Nakhon Phanom at that time. It was construct as the residence of monks and novices in the form of a 2-storey brick and mortar building that was influenced by the western style imported by those Vietnamese craftsmen. The building has a wall bearing structure, while the roof structure and the second floor were made of wood. The doors and windows had their curved architraves influenced by the western buildings.

\section{ARCHITECTURAL EVALUATION THROUGH STAKEHOLDERS' PARTICIPATION}

From the conceptual framework of architectural evaluation in Figure 1, the architectural appraisal from stakeholders' viewpoints can be indicated as follow;

\subsection{Viewpoint of Stakeholders Related to Luang Poo Si That House}

Luang Poo Si That House has its historical significance due to its relationship with development on the construction of Phra That Tha Uthen stupa. Furthermore, this building has its architectural characteristic expressing the identity of Tai-Yoh ethnic group. The building has architectural significance in various dimensions: (1) It is the best example of that type of building at the community/local level. (2) It is the only one building of that type that remains in the community area. (3) It is an extraordinary building at the community level. (4) It is the building that has special construction technique or skill at the community/local level. (5) It is a rare building at the community level. (6) The location of the building reflects space allocation in the temple area by taking into consideration the belief of space allocation in the temple. Therefore, the building has its townscape significance as follows: (1) The building is an important composition of the district. (2) Genuineness of the building leads to values for its location or community. (3) The building has its significance when it is gathered as a group of buildings. (4) The building is an important composition to enhance the significance of other buildings. It is regarded as an evidence for reflecting history about the development of Wat Phra That Tha Uthen.

\subsection{Viewpoint of Stakeholders Related to Ho Chaek}

Ho Chaek is the main composition of the temple style of Lan Chang Cultural Group in Nakhon Phanom province. It is constructed by Vietnamese craftsmen with expertise in construction of brick and mortar buildings as well as construction technique and method influenced by the western architecture. Therefore, this building has its architectural significance as a representative of the age and construction technology of brick and mortar building in the western style. Furthermore, the building is an important composition in the aspect of townscape significance of Wat Phra That Tha Uthen.

\subsection{Viewpoint of Stakeholders Related to Phra That Tha Uthen Stupa}

Phra That Tha Uthen Stupa has its significance related to memory and local history, especially in the provincial area of Nakhon Phanom, Nong Khai, Udon Thani, Loei and Bolikhamsai Province, Lao PDR. Its architectural significance is being the prototype of other Phra That e.g. Phra That Non Tan at Tha Uthen District and Phra That Phutthabat Bua Bok at Ban Phue District, Udon Thani Province and Phra That Phra Baht Phonsane, Thaphabath District, Bolikhamsai Province, Lao PDR. Phra That Tha Uthen stupa has its genuineness in shape and materials that truly maintain artistic values. Furthermore, it is an important composition of Tha Uthen's Old Community District and is the townscape significance with its surrounding context both in the community and the city. The historical and architectural significance as well as its being the representative of Tha Uthen Community are the important ground for community development in terms of tourism and revenue, and hence, having financial significance.

\subsection{Viewpoint of Stakeholders Related to Sim}

Sim is a representative of the historical change of Thailand's government system for its reflection of the changes in local way of people's thoughts at that time, which affected the architecture's physical changes. Thus, Sim of Wat Phra That Tha Uthen has its historical significance at the national level.

\subsection{Viewpoint of Stakeholders Related to the Monk House}

The Monk House is a building that has architectural significance as the representative of the age and construction technology of brick and mortar buildings in the form of western style. In addition, it is an important composition in terms of townscape significance of Wat Phra That Tha Uthen.

\section{DISCUSSION}

From the architectural evaluation of the 5 buildings through stakeholders' participation under the conceptual framework of 6 aspects of architectural values, it was found that most of the 5 stakeholder groups have their viewpoints in the dimension of architectural values in the same direction. This is the tendency that reflects positive opinions towards architectural values, namely, historical and cultural significance, architectural significance, and townscape significance. On the other hand, stakeholders reflect differences of viewpoints for some significance, especially some issue of value in intangible dimension that cannot be found through physical survey or direct interview (Table 1). It was found that interpretation and acknowledgement of architectural values in different viewpoints lead to changes and methods in conservation depending on each stakeholders' responsibility which can be discussed as follows:

\subsection{Luang Poo Si That House}

It was found that all stakeholders weighed the historical and cultural significance, architectural significance, townscape significance, and educational significance in varied levels. Luang Poo $\mathrm{Si}$ That House is believed to have its main significance on the architecture rather than on other dimensions. 
Moreover, it was found that the stakeholders have different opinions in the value dimensions including lifestyle, technology and locality and in the dimension of genuineness of the building, which leads to values for location and community as well as suitability of the building usage at present.

The architectural values from the reflection of a group of stakeholders included the fact that the building has its historical significance related to the local culture and hence having architectural significance. It is an important composition in terms of the relations to other buildings in the site. Therefore, the building has significant values in the dimension of history and culture, architecture and townscape aspects.

The suggestions for conservation are based on the method of architectural restoration that has not been emphasized in terms of maintaining genuineness of materials, but has been focused on as far as the meaning of communication and memory of important persons are concerned. There is also a future goal for adapting the use of the building to become Luang Poo Si That Museum. However, before the operation there were suggestions from people in that area to move the house back to its former location in order to maintain the building's history as it was in 1997. After discussion, suggestion was made to keep it at the present location to be in accordance with values and townscape significance.

\subsection{Ho Chaek}

It was found that all of the stakeholders weighed the townscape significance and suitability significance of Ho Chaek at the highest level, followed by the historical and cultural significance, and architectural significance. Furthermore, stakeholders have different opinions in the dimension of educational significance. From the viewpoints of the Fine Arts Department and community philosophers, Ho Chaek has its educational significance due to the building being regarded as an important composition of the stupa that should be studied for its values and should be properly conserved.

The results of architectural evaluation from the viewpoint of stakeholder groups show that Ho Chaek has its importance in the dimensions of townscape significance, architectural significance, historical and cultural significance. Ho Chaek has thus been developed and repaired continually by relevant individuals, most of whom place importance on the overall acknowledgement in the aspect of landscape. As this building is the main composition for doing activities in the temple area, the opinion on architectural and historical values is not remarkable. The guideline for conserving this building made by the people in the area includes changes that focused on development more than conservation. Ho Chaek is still in good condition and can accommodate activities at present, showing that Ho Chaek is an architecture with its values in the aspect of suitability and usage. Changes that directly affect Ho Chaek are not severe towards the overall values of the building. One issue to note is its valuable identity, i.e., the stucco and system of traditional roof structure, even though roofing materials are modernized already.

\subsection{Phra That Tha Uthen Stupa}

Phra That Tha Uthen Stupa. It was found that all of the stakeholders rated the significance of Phra That Tha Uthen stupa at the high level in all aspects, i.e., historical and cultural significance, architectural significance, townscape significance, financial significance, suitability significance and educational significance. However, stakeholders' opinions differ in the dimension of physical damage of Phra That Tha Uthen stupa.
Phra That Tha Uthen stupa has its significant value in all 6 aspects of historical and cultural significance, architectural significance, townscape significance, financial significance, suitability significance and educational significance. Phra That Tha Uthen stupa is associated with historical events and is an architecture with identity as an important monument in the Mekong Basin. Phra That Tha Uthen, therefore, has its importance at the national and regional level. It is registered as a national monument site that leads to conservation processes under the concept of monument site conservation implemented by the Fine Arts Department.

Phra That Tha Uthen stupa has been promoted as a cultural tourist attraction of Nakhon Phanom Province and this makes the stupa possessing its financial significance. The environments in the site are improved for supporting tourism. Nonetheless, the improvement is based on the development plan to attract tourists that eventually does not conform to the concept of architectural conservation.

\subsection{Sim}

It was found that all of the stakeholders weighed the historical and cultural significance at the highest level, followed by townscape significance. The stakeholders have different opinions in the value dimension of educational significance.

The Fine Arts Department and community philosophers believed that Sim has its relationship with the changes of national situation, which led to changes of Sim. Therefore, it is suggested that historical circumstances should be studied to fulfil the local history.

The results of architectural evaluation from the viewpoints of stakeholder groups show that Sim has its distinct importance in historical and cultural significance related to changes at the national level. The architectural significance, townscape significance, financial significance, suitability significance and educational significance are not outstanding because Sim has been affected from the changing of local style and identity into the style of the central region. Nowadays, building conservation is in the form of restoration and changing of usage to be able to meet community activities.

\subsection{The Monk House}

It was found that all of the stakeholders weighed the townscape significance at a very high level, followed by the architectural significance, historical and cultural significance. However, the stakeholders have different opinions in the dimension of lifestyle, technology, locality and suitability of the building usage at present.

The Monk House Building has its significant value in architectural significance and townscape significance. It is quite distinguished from other buildings in terms of historical and cultural significance, financial significance, suitability significance and educational significance. Even though the evaluation rating of this building is not high compared to other buildings, this monk house is important at the community and district levels due to its architectural style that reflects historical age. Therefore, this building is looked after and repaired by the budget of the temple. The suggested conservation of this building is a restoration for retaining its original conditions. The conservation of the monk house is only for maintaining the architecture, but it also has suitability significance with potentiality to extend its usage for both learning and other activities. 


\begin{tabular}{|l|l|}
\hline & LEGEND \\
\hline & High in architectural value \\
\hline & Medium in architectural value \\
\hline & Low in architectural value \\
\hline
\end{tabular}
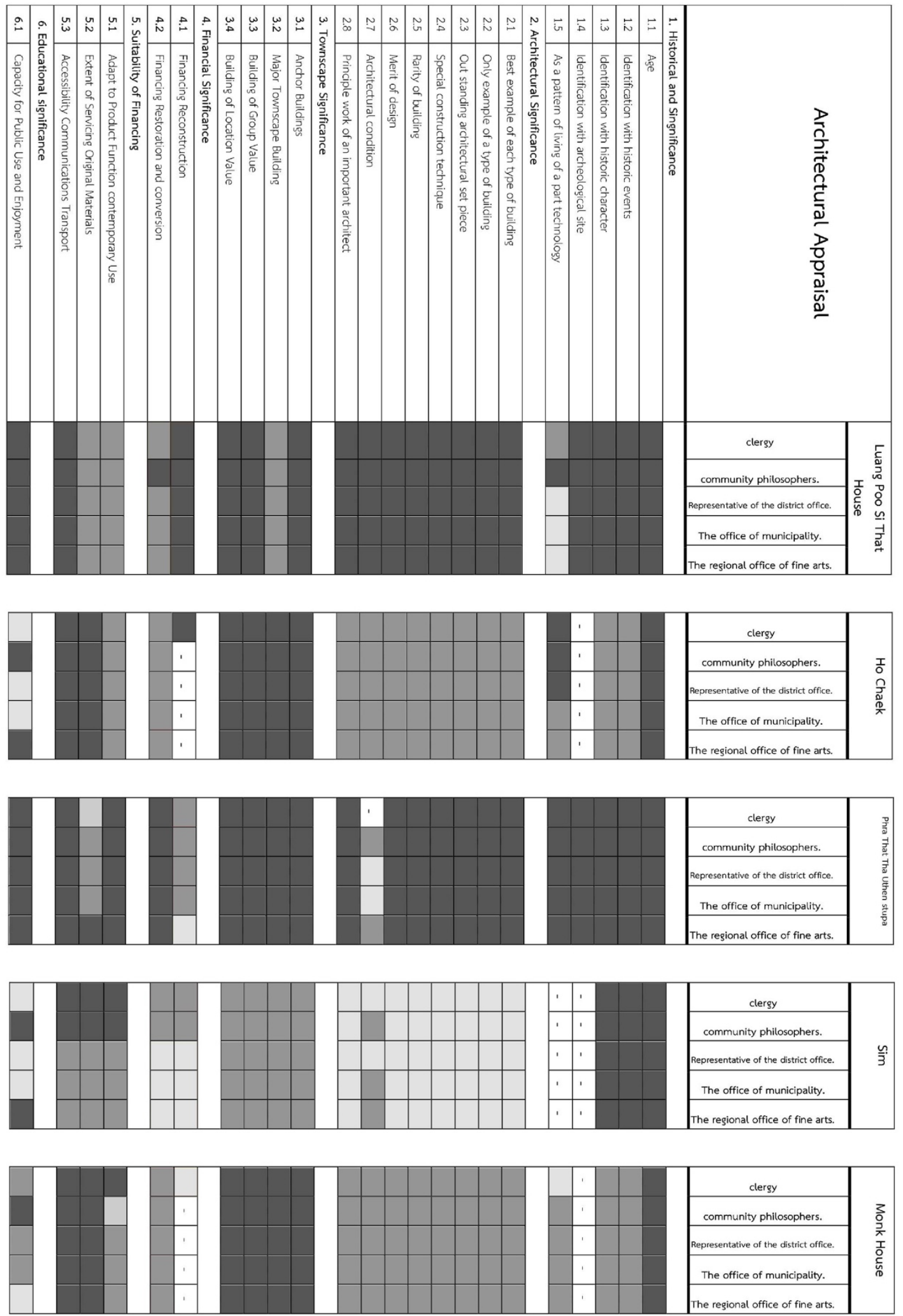

Table 1. Architectural evaluation of the 5 buildings through stakeholders' participation. 


\section{CONCLUSION}

The architectural evaluation through stakeholders' participation is a tool for examining the significant tendency of architectural values and reflecting the viewpoints of those stakeholders that lead to an analytic process to stipulate guidelines for proper architectural conservation. Such method is a tool for finding out a good conclusion in the dimension of architectural values among conflict situations in the area. The architectural evaluation through stakeholders' participation, therefore, is not the only method to understand architectural values from stakeholders' viewpoints, but also a process for minimizing conflicts on decision making for suitable operations derived from different perspectives in conserving valuable architecture.

The results and processes of architectural evaluation from stakeholders in this study reveal that there are still certain issues about the understanding and additional suggestion of concept on architectural conservation as follows:

1. For more accuracy of results on architectural evaluation through stakeholders' participation, data and information related to development and history of such area should be assessed to related and specified groups of stakeholders in the area from the past until now and to clearly determine appropriate participants prior to the process of architectural evaluation.

2. If the results of architectural evaluation reflect further differences of stakeholders' viewpoints and are not able to describe tendency of architectural significance, this may indicate that related stakeholders are granted with different levels of architectural data and information. Therefore, learning processes for transferring and exchanging of data about the history and development of architecture should be created for shared understanding prior to implementation of architectural evaluation.

\section{ACKNOWLEDGEMENTS}

This research is granted by Thailand Research Fund: Master Research Grants (TRF-MAG), and the article is partially supported by the Center for Research on Plurality in the Mekong Region (CERP), Faculty of Humanities and Social Sciences, Khon Kaen University.

\section{REFERENCES}

Feilden, B. M. 1995. Conservation of Historic Building. Great Britain: Bath Press.

Kanchana Kaewthep. 1995. Working Tool of Community Culture. Catholic Council of Thailand. Bangkok.

Office of Environmental Policy and Planning. 2007. Practice Guideline and Standard for Conservation, Development and Rehabilitation of Environmental Quality in the Area of Old Town and Surrounding Area. Bangkok. Bangkok, Office of Environmental Policy and Planning.

Office of Environmental Policy and Planning. 2015. Using the Quality Standard of Cultural Environment in Traditional Communities to practice the Plan of Conservation Management and Environmental Improvement at Tha Uthen Old Community. Nakhon Phanom. Bangkok, Office of Environmental Policy and Planning.
Prasong Eiamanant. 2017. A Conservation Guideline for Local Communities in Northern Region. Printing House. Siam Books and Publications Co., Ltd.

Pranom Tansukanun. 2016. Urban Conservation. Bangkok, Faculty of Architecture, Chulalongkorn University Press.

Pinrat Kanchatthiti. 2009. Cultural Heritage Conservation and Community. Bangkok, Faculty of Architecture, Chulalongkorn University.

Somchart Chungsiriarak. 2015. Background, Concept, Theory and Operation of Monument Sites Conservation. Bangkok, Faculty of Architecture. Silpakorn University.

Sittinut Praputnitisarn. 2003. Participatory Action Research. Faculty of Social Sciences. Chiang Mai University.

Sittiporn Piromruen. 2003. Urban Conservation and Cultural Environment. Na Jua Journal of History, Architecture and Thai Architecture. Bangkok, Faculty of Architecture. Silpakorn University.

Thada Sutthitham. 1997. International Conference on Conservation and Restoration of Local Architecture and ICOMOS-CIAV General Conference. ASA Journal Vol. 8 August.

Thada Sutthitham. 1998. Conservation of the Oldest Sim in Isan. Isan-Architecture Journal. Faculty of Architecture. Khon Kaen University. Vol. 1, 2541.

Yongtanit Pimonsathean. 2013. Critical Issues on the Conservation of Historic Urban Community. Na Jua Journal of History, Architecture and Thai Architecture. Faculty of Architecture. Silpakorn University. 